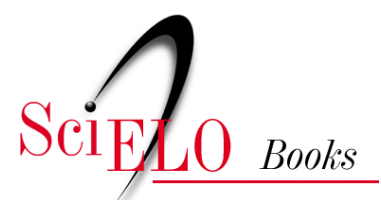

\title{
22. O Desafio da Febre Amarela
}

\author{
Joffre Marcondes de Rezende
}

\section{SciELO Books / SciELO Livros / SciELO Libros}

REZENDE, J. M. O Desafio da Febre Amarela. In: À sombra do plátano: crônicas de história da medicina [online]. São Paulo: Editora Unifesp, 2009, pp. 221-226. História da Medicina series, vol. 2. ISBN 978-85-61673-63-5. https://doi.org/10.7476/9788561673635.0023.

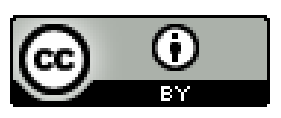

All the contents of this work, except where otherwise noted, is licensed under a Creative Commons Attribution 4.0 International license.

Todo o conteúdo deste trabalho, exceto quando houver ressalva, é publicado sob a licença Creative Commons Atribição 4.0.

Todo el contenido de esta obra, excepto donde se indique lo contrario, está bajo licencia de la licencia Creative Commons Reconocimento 4.0. 


\title{
O Desafio da Febre Amarela
}

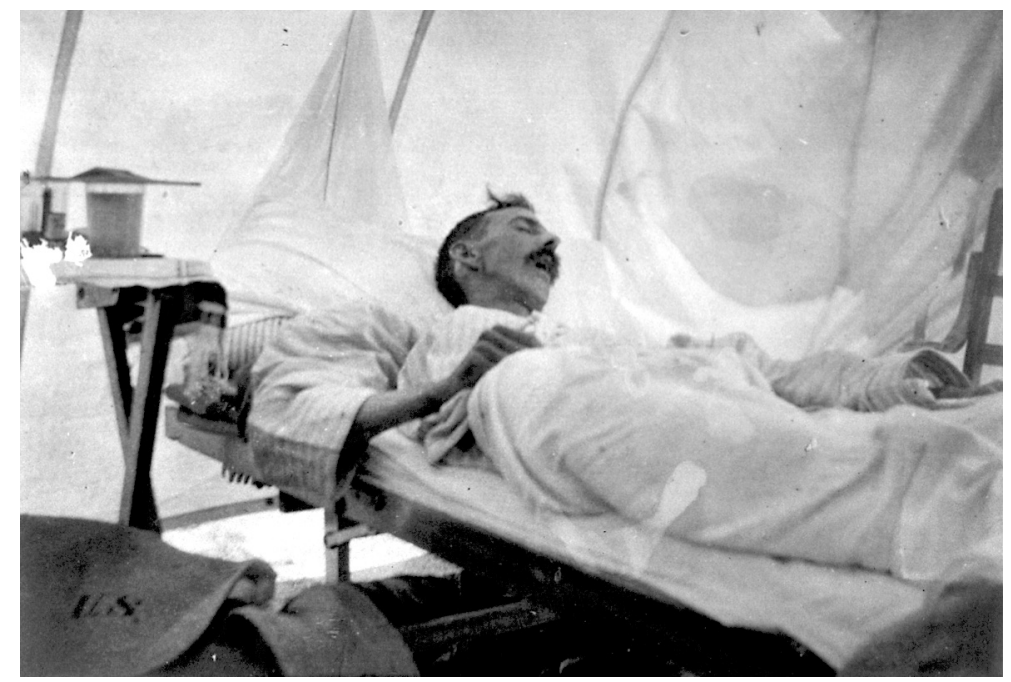

Paciente com febre amarela em um hospital de Siboney, Cuba, julbo de I 898.

\begin{abstract}
A febre amarela constituiu durante quatro séculos um permanente deA safio à medicina.
\end{abstract}

Desconhecida na Antiguidade, sua história coincide com a descoberta do Novo Mundo. Apesar da controvérsia existente sobre sua origem, tudo indica tratar-se de uma doença autóctone da América Central.

A denominação de febre amarela foi empregada pela primeira vez por Griffith Hughes, em seu livro Natural History of Barbadoes, publicado em I $75^{\circ}$, em alusão às duas manifestações clínicas mais características da enfermidade: a febre e a icterícia. Antes, a doença era conhecida pelos mais variados nomes (Andrade e Duarte, I956, p. 206).

A febre amarela chegou ao Brasil no século XVII, trazida por via marítima em embarcações procedentes das Antilhas. A primeira epidemia ocorreu em Pernambuco, em I685, e foi tema de um dos três primeiros livros de medicina escritos no Brasil, intitulado Tratado Único da Constituição Pestilencial de Pernambuco, de autoria de João Ferreira da Rosa, publicado em Lisboa em I694. 
Em I686 a febre amarela irrompeu sob forma epidêmica na Bahia, causando muitas vítimas conforme narra o historiador Rocha Pitta em sua História da América Portuguesa, publicada em Portugal em I730.

No século XVIII não há registro de epidemias de febre amarela no Brasil, a qual ressurgiu no século XIX, tanto sob a forma endêmica como epidêmica (Santos Filho, I99I, pp. I70-I76).

A etiologia da febre amarela foi objeto das mais variadas especulações. Antes da era microbiana, as mais disparatadas causas foram apontadas, além de castigo divino e punição dos pecados: eclipses do sol e da lua, condições climáticas, falta de chuvas e de trovoadas, emanações provenientes da decomposição de matéria orgânica, contaminação da água por substâncias pútridas, indigestão, exposição excessiva ao calor no verão, fadigas do corpo e do espírito etc. (Franco, I960, p. 45).

Em relação ao modo de transmissão havia duas doutrinas que dividiam as opiniões: a que admitia o contágio direto de pessoa a pessoa e a que não admitia esse contágio. Ambas contavam com defensores de prestígio e renome.

Após os trabalhos iniciais de Pasteur e Koch demonstrando a natureza infecciosa de muitas doenças, era natural que também se procurasse um micróbio para a febre amarela. Em I 878, em Filadélfia, nos Estados Unidos, Richardson descreveu uma bactéria que seria a causadora da febre amarela, denominando-a Bacteria sanguinis febris flavae.

Freire Júnior, no Brasil, em I 880, responsabilizou um parasito por ele denominado Cryptococcus xanthogenicus, e chegou a preparar uma vacina com a qual inoculou 2.4I 8 pessoas. Foi, portanto, um precursor da ideia de combater a febre amarela por meio da vacinação preventiva. A vacina não demonstrou eficácia e o Cryptococcus xanthogenicus não existia; os supostos germes eram apenas hemácias alteradas, conforme comprovou Araújo Goes em I 885 .

Outros possíveis "micróbios" responsáveis pela febre foram descritos por diferentes pesquisadores, tais como o Bacillus $x$ havanensis, por Sternberg nos Estados Unidos, em I887, o Bacillus icteroides, por Sanarelli em Montevidéu, em I897; a Leptospira icteroides, por Noguchi em Guaiaquil, em r9i 8 (Idem, pp. 49-50).

A ideia da transmissão pelo mosquito ocorrera a Josiah Nott, nos Estados Unidos, já em I 848, e a Beauperthuy, na Venezuela, em I 853 . Este últi- 


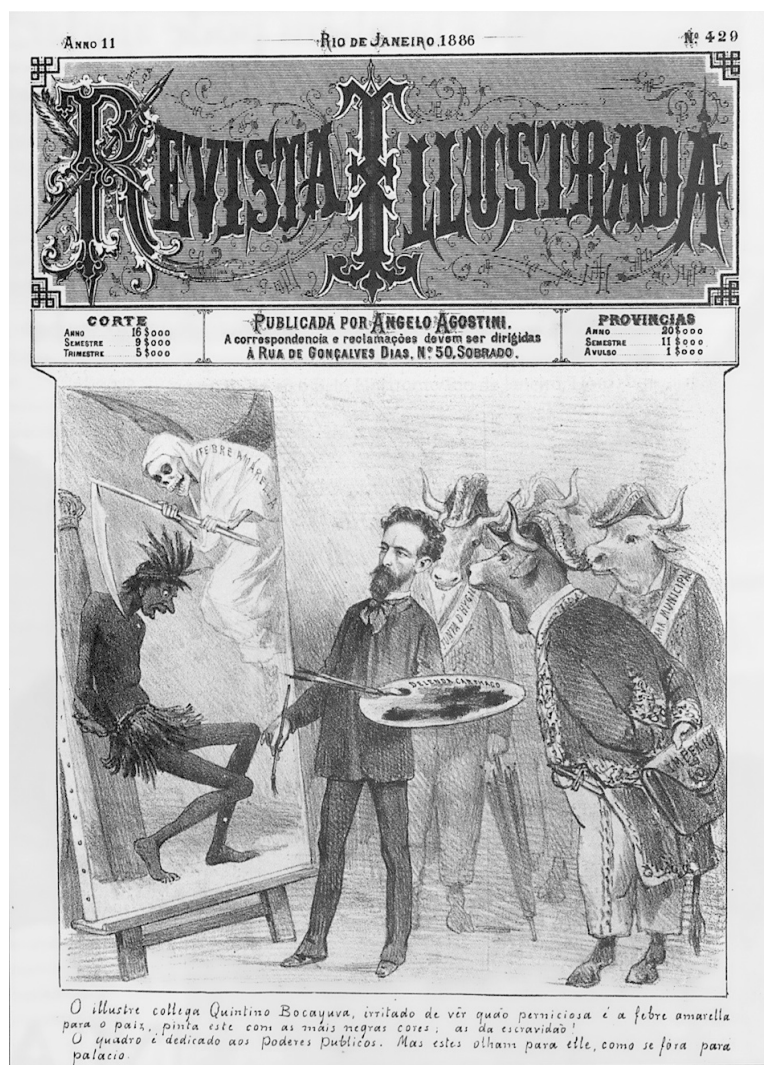

A capa da Revista Illustrada, de I886, registra Quintino Bocaiuva pintando um quadro alusivo à febre amarela, enquanto os poderes públicos assistem impassíveis à cena, representados como vacas. Desenho de Angelo Agostini.

mo autor, observando que a febre amarela ocorria em cidades litorâneas, admitia que os mosquitos alimentavam-se de restos de peixes e da fauna existente em pântanos, transmitindo ao homem "sucos sépticos" que produziam hemólise.

No Brasil, Filogonio Utinguassu foi quem primeiro defendeu a ideia da transmissão do agente da febre amarela pelo mosquito, em sessão da Academia Imperial de Medicina de 27 de outubro de I 88 . Sua comunicação não despertou maior interesse (Idem, p. $5 \mathrm{I}$ ).

Em Cuba, Carlos Finlay cedo se convencera de que a transmissão se processava através de uma única espécie de mosquito, o Culex fasciatus (Aedes 
aegypti). Na Conferência Sanitária Internacional, realizada em Washington em I 88 I, Finlay defendeu pela primeira vez o combate aos mosquitos como forma de prevenção da febre amarela. Suas ideias não foram levadas a sério.

Para comprovar sua teoria, logrou transmitir a doença em cinco voluntários que se deixaram picar por mosquitos que haviam sugado antes doentes de febre amarela. Comunicou sua experiência à Academia de Ciências de Havana, que a acolheu com desinteresse. No decurso de dezenove anos, repetiu a experiência em IO2 pessoas, tendo conseguido a transmissão de formas benignas da doença em várias delas. Em I 897 propôs ao governo dos Estados Unidos um plano detalhado para erradicar a febre amarela de Havana pelo combate ao mosquito transmissor. Como das outras vezes, não teve êxito (Idem, pp. 56-58).

Somente em I900, após o término da guerra hispano-americana, o Serviço de Saúde do Exército Americano interessou-se pelo problema em decorrência de mais de duzentos óbitos por febre amarela ocorridos entre os seus soldados sediados em Cuba. Foi nomeada uma Comissão, chefiada pelo major-médico Walter Reed que, juntamente com James Carrol, Jesse Lazear e Aristides Agramonte, deram início em Havana às experiências que culminaram com a comprovação, em caráter definitivo, do acerto da teoria de Finlay, de que a febre amarela não é contagiosa e que sua transmissão se dá através do mosquito por ele indicado. Jesse Lazear foi vítima de exposição ao vetor e faleceu de febre amarela (Idem, pp. 58-63).

No Brasil, Emílio Ribas, então diretor do Serviço Sanitário do Estado de São Paulo, tomando conhecimento dos trabalhos da Comissão Americana em Cuba, decidiu iniciar em I90 I uma campanha de combate ao mosquito em Sorocaba, interior de São Paulo, onde se registrara uma epidemia no ano anterior, com mais de dois mil casos notificados. O mesmo foi feito em São Simão e Ribeirão Preto, onde também haviam sido registrados casos de febre amarela.

Como ainda houvessem críticas e dúvidas sobre a validade das experiências realizadas em Cuba, Emílio Ribas decidiu repeti-las com algumas variantes em São Paulo, contando para isso com a colaboração de Adolpho Lutz, Luiz Pereira Barreto, Adriano de Barros e Silva Rodrigues. Os experimentos realizados em voluntários, dentre os quais os próprios médicos e três imigrantes italianos recém-chegados ao Brasil, foram de tal ordem que até os mais céticos 
ficaram convencidos da não contagiosidade da febre amarela e da responsabilidade do mosquito Stegomyia fasciata, como se denominava então, o Aedes aegypti, na sua transmissão (Bacellar, 1963, pp. 24I-246).

No século XIX a febre amarela grassava na cidade do Rio de Janeiro sob forma endêmica, com surtos epidêmicos. No período de I850 a I902 haviam sido registrados na antiga capital federal, 58063 óbitos por febre amarela (Franco, op. cit., p. 43).

A campanha contra a febre amarela no Rio de Janeiro é uma das páginas gloriosas da medicina brasileira, que consagrou o nome de Oswaldo Cruz e projetou o nosso país no cenário internacional. A epopeia de Oswaldo Cruz é bem conhecida e não será aqui relembrada. $\mathrm{O}$ que, às vezes, deixa de ser mencionado é que o presidente Rodrigues Alves perdera uma filha vítima de febre amarela, o que certamente deve ter contribuído para o apoio que ele dispensou a Oswaldo Cruz.

Tinha-se a impressão de que a febre amarela era uma doença essencialmente urbana, cujo transmissor estava adaptado ao domicílio humano e, por isso, poderia ser erradicada. Verificou-se, posteriormente, a existência de uma forma silvestre da febre amarela, tendo como animais reservatórios os primatas, e como transmissores outros flebótomos dos gêneros Aedes e Haemagogus (Soper, I936, pp. 31-70).

Tornou-se evidente, portanto, a impossibilidade de extinguir-se a febre amarela e surgiu o derradeiro desafio: a prevenção por meio de uma vacina que fosse eficaz e bem tolerada.

Desde I90I já se sabia que o agente da febre amarela deveria ser um vírus e não uma bactéria, pois James Carrol conseguira transmitir a doença pela injeção subcutânea do filtrado do soro sanguíneo de um enfermo.

A primeira vacina, após a comprovação da transmissão vetorial, foi preparada por William Gorgas em Havana, em I901, a partir de mosquitos infectados. Foram inoculadas dezoito pessoas, das quais oito adquiriram a infecção, com três óbitos. Estes resultados levaram ao abandono da ideia da vacinação com o mosquito.

Em 1927, Stokes demonstrou que era possível infectar o macaco rhesus com o vírus da febre amarela (Franco, op. cit., p. I28). A dificuldade de obter e de trabalhar com esta espécie, entretanto, constituía um entrave ao progresso dos estudos experimentais. 
Em 1930, Max Theiler, um médico sul-africano que se dedicava ao estudo da febre amarela nos Estados Unidos, conseguiu infectar camundongos, injetando diretamente no cérebro desses animais tecido hepático de macaco rhesus infectado. $\mathrm{O}$ vírus obtido de camundongos conferia imunidade ao macaco e ao homem, porém não pôde ser usado como vacina por sua ação neurotrópica. Algumas pessoas inoculadas com este vírus por pesquisadores franceses morreram com encefalite.

Max Theiler e seus colaboradores da Fundação Rockefeller passaram, então, a cultivar o vírus em embriões de camundongos, dos quais antes se retirava o sistema nervoso e, a seguir, em embriões de galinha também desprovidos de sistema nervoso. Mantiveram vivo o vírus durante três anos, em sucessivas passagens em embriões assim preparados e obtiveram um mutante conhecido por I7D, que se mostrou imunizante e sem qualquer risco para o homem (Schiller, I99I, pp. 639-646).

Esta vacina foi testada em grande escala no Brasil entre os anos de 1937 a 1940, com bons resultados. Em I947, após a Segunda Guerra Mundial, já haviam sido utilizadas em todo o mundo 28 milhões de doses.

Max Theiler recebeu, com justiça, o prêmio Nobel de Medicina em I95 I. $\mathrm{Na}$ ocasião, respondendo a um repórter, disse muito modesto: "É certo que trabalhamos arduamente, mas também tivemos muita sorte”.

\section{Referências Bibliográficas}

Andrade, G. O. \& Duarte, E. Morão, Rosa e Pimenta. Recife, Arquivo Público Estadual de Pernambuco, I956.

Bacellar, R. C. Brazil's Contribution to Tropical Medicine and Malaria. Rio de Janeiro, Gráfica Olímpica Editora, I963.

Franco, O. História da Febre Amarela no Brasil. Rio de Janeiro, Ministério da Saúde, I960.

Santos Filho, L. História Geral da Medicina Brasileira. São Paulo, Hucitec/Edusp, I99I.

Schiller, N. “Max Theiler”. In Magill, F. N. The Nobel Prize Winners. Physiology or Medicine. Pasadena, Salem Press, I99I.

Soper, F. L. "Febre Amarela Silvestre: Novo Aspecto Epidemiológico da Doença”. Boletim de Higiene e Saúde Pública, Io, pp. 3 I-70, 1936. 